heater fuel is probably best omitted. On pressurized aircraft the air temperature rise through the cabin blowers is often sufficient to maintain comfort without operating the heaters. The assumption that the heaters will operate for any specific period is usually badly in error.

If the operator is concerned with only one type of aircraft and only one route, the fuel reserve requirements with the exception of fuel-to-alternate can be built right into the flight planning fuel graph, including, if desired, fuel for 50 per cent (?) heater operation. In addition it is also possible to print many of the standard entries right on the form.

To facilitate comparison between flight plan and flight log it has been found that an actual time of arrival (A.T.A.) column on the flight plan fulfils this duty admirably.

Finally there is the question of comparing flight times on various tracks. This is completely useless unless the forecast chart is absolutely reliable. Planned circumnavigation of pressure centres becomes detrimental in practice unless the centres actually are in the position forecast. A more consistent method of reducing flight time is to base all navigation on the great circle and to use the single drift (single heading) technique whenever practicable.

I hope that these observations on Mr. Hamer's useful paper may be of some interest to your readers.
Canadian Pacific Air Lines Ltd., Vancouver, A.M.F., B.C.

\author{
Yours truly, \\ F. D. P. WICKER, \\ Chief Navigator.
}

\title{
RADAR USAGE AND SPEED IN FOG
}

SIR,

A voyage to Australia has kept me out of touch with things for rather a long time, but I return to an interesting situation which Captain Wylie's letter (Vol. IV, No. 4, p. 430) on my paper has produced. May I, in turn, be allowed to comment on his letter?

Undoubtedly, as Captain Wylie writes, a steady and predictable course (and speed) on the part of pedestrian or ship gives motorist and radar navigator something to work on. 'Radar Usage and Speed in Fog', which confined itself entirely to the aspect of speed, was an attempt to bring that something into the realm of practical politics-an attempt to find a means by which each individual ship can assess a speed for herself which will permit all radar-using ships to maintain course and speed whilst the outermost third of detection range is being used up. The paper endeavours to shed a little light on the mystery which permeates the instruction that ' . . in fog . . . (every vessel shall) go at a moderate speed. . . .' Concepts of moderate speed may be promulgated, but the proof of the pudding lies always in the eating, and, to the misfortune of the seaman, the eating is done by an Admiralty Court. Let us endeavour to keep our cookery away from Admiralty lawyers.

Like the Collision Regulations, the paper makes no attempt to give precise instruction on how a ship should be manoeuvred. Basic principles of seamanship are taught in the navigation schools, but the timely helm action which so often 
averts collision in fog is the instantaneous reaction of experience-something which can be absorbed, may be innate, but cannot be taught.

On the vagaries of human nature (Captain Wylie's letter, para. 3), the Collision Regulations, with the possible exception of Article 27, are a valiant attempt to curb vagaries. Article 27, in its careful wording, makes admission of defeat in an impossible task and commits the ultimate freedom of wise action to the possessor of common sense. That article paraphrases the commandment'Thou shalt not be found out.'

But does possession of a radar set add new variables to the intangibles of seamanship in low visibility? Surely the non-radar navigator's greatest difficulty lies in estimating, with some degree of accuracy, the distance he can see. On this estimate he must decide his speed, and temptation to overestimate grows as the uneventful hours creep past. Only through fortuitous sighting of another ship can he make a reasonable guess at the range of visibility-and the ship he has sighted lies in one direction only. An efficient radar set efficiently operated gives a definite safe estimate of the detection range of the type of target likely to be met-under the unextreme conditions of wave clutter usually experienced in fog or mist, that is. Efficient radar sets can be obtained, and their degree of efficiency is demonstrable by an efficient overall monitor. Efficient operation can be attained by a little study of the physics of radar and of the limitations of the navigational radar set installed. Here we have an instrument which tells the seaman the distance at which he can reasonably expect to 'see' his target. Surely this is major reduction in the greatest variant of all.

If an analysis could be made of how radar was involved in the more recent strandings and collisions, the analysis would surely indicate failure of personnel, not failure of radar. The failures indicated would probably be failure to use the radar when its use would have saved the ship; failure to keep radar watch on a range view suitable to the immediate job in hand-avoidance of collision; and failure to use the swept gain circuit for the purpose of its invention-avoidance of saturation of the close-range P.P.I. by wave clutter.

Alfred Holt \& Co., Liverpool, 2.
Yours faithfully, E. M. Rовв,

Shipmaster. 